Case Report

\title{
An Unusual Trocar Site Hernia after Prostatectomy
}

\author{
Ryan K. Schmocker and Jacob A. Greenberg \\ Department of Surgery, University of Wisconsin School of Medicine and Public Health, Madison, WI, USA \\ Correspondence should be addressed to Jacob A. Greenberg; greenbergj@surgery.wisc.edu
}

Received 1 July 2016; Accepted 11 August 2016

Academic Editor: Gregorio Santori

Copyright (c) 2016 R. K. Schmocker and J. A. Greenberg. This is an open access article distributed under the Creative Commons Attribution License, which permits unrestricted use, distribution, and reproduction in any medium, provided the original work is properly cited.

Trocar site hernias are rare complications after laparoscopic surgery but most commonly occur at larger trocar sites placed at the umbilicus. With increased utilization of the laparoscopic approach the incidence of trocar site hernia is increasing. We report a case of a trocar site hernia following an otherwise uncomplicated robotic prostatectomy at a $12 \mathrm{~mm}$ right lower quadrant port. The vermiform appendix was incarcerated within the trocar site hernia. Subsequent appendectomy and primary repair of the hernia were performed without complication.

\section{Introduction}

Trocar site hernias are rare complications after laparoscopic surgery with the overall incidence of $0-5.2 \%$ [1]. However, with the increasing number of laparoscopic procedures that are performed, these are becoming increasingly common. These hernias are most often associated with $\geq 10 \mathrm{~mm}$ trocars at the umbilical site [1], though there have been reports of trocar site hernias at other locations and with varying port sizes. Here we report an unusual case of a right lower quadrant trocar site hernia following robotic prostatectomy.

\section{Case}

A 66-year-old male, with a BMI of approximately $28 \mathrm{~kg} / \mathrm{m}^{2}$, presented to our surgery clinic for a symptomatic right lower quadrant trocar site hernia, following robotic assisted radical prostatectomy. In December of 2010 he underwent an uncomplicated robotic assisted radical prostatectomy. At the time of the operation a $12 \mathrm{~mm}$ trocar was placed in the right lower quadrant, and it is unclear from the operative note whether the fascia was closed at the conclusion of the operation. He recovered from the surgery without issue but unfortunately developed widely metastatic disease over the next 18 months. Upon presentation to our clinic in May of 2012, he was complaining of a two-week history of right lower quadrant pain and a newly discovered mass in the vicinity of a previous trocar site. He initially noted the onset of the pain when performing pull-ups at a local gym, at which time he noted pulling sensation in the right lower quadrant. Following the initial onset of symptoms, he continued to have pain in the area and noted an intermittent bulge as well. He presented for initial evaluation by his primary care provider who obtained a CT scan of the abdomen and pelvis. The scan revealed a $10 \mathrm{~mm}$ right lower quadrant hernia with herniated fat and a tubular structure which was read as a possible omental vessel, with concern for incarceration (Figure 1). Upon reviewing the CT with the patient in clinic it was felt that the tubular structure was actually the vermiform appendix and thus laparoscopic incisional hernia repair was recommended.

He presented the following week for an elective hernia repair. Pneumoperitoneum was established through a $12 \mathrm{~mm}$ umbilical Hasson port. Two additional $5 \mathrm{~mm}$ ports were then placed, one in the left lower quadrant and one in the suprapubic area. On inspection of the abdomen there was no evidence of peritoneal disease. The right lower quadrant was then inspected, and as suspected from preoperative imaging a small hernia was identified which contained an incarcerated appendix (Figure 2). The appendix was reduced from the hernia and during the reduction the mesoappendix was injured so a standard laparoscopic appendectomy was performed. Due to the concern for mesh infection following the appendectomy, the hernia was then closed primarily 

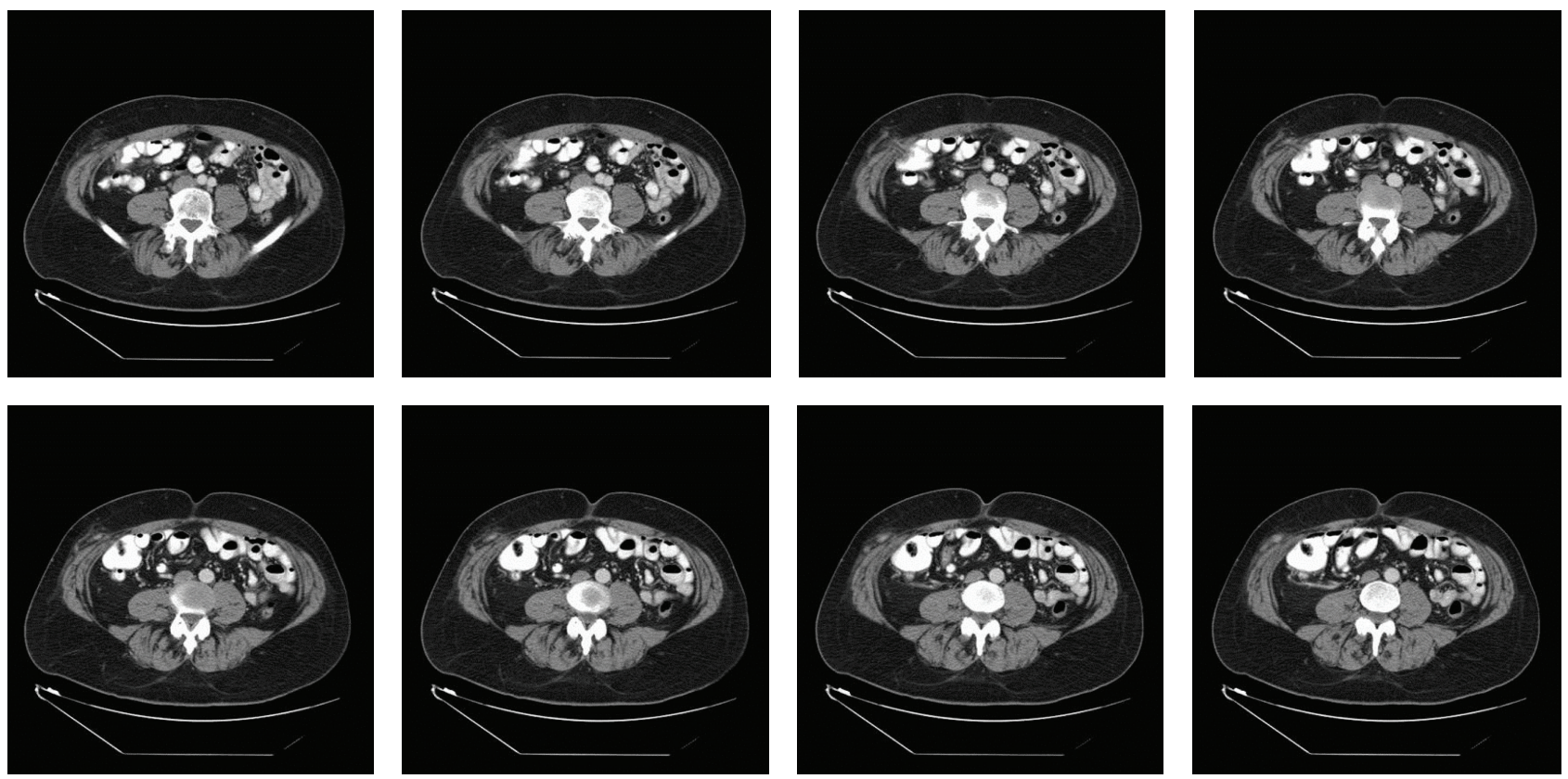

FIGURE 1: Axial images from a preoperative computed tomography scan demonstrating a right lower quadrant hernia containing fat and the appendix.
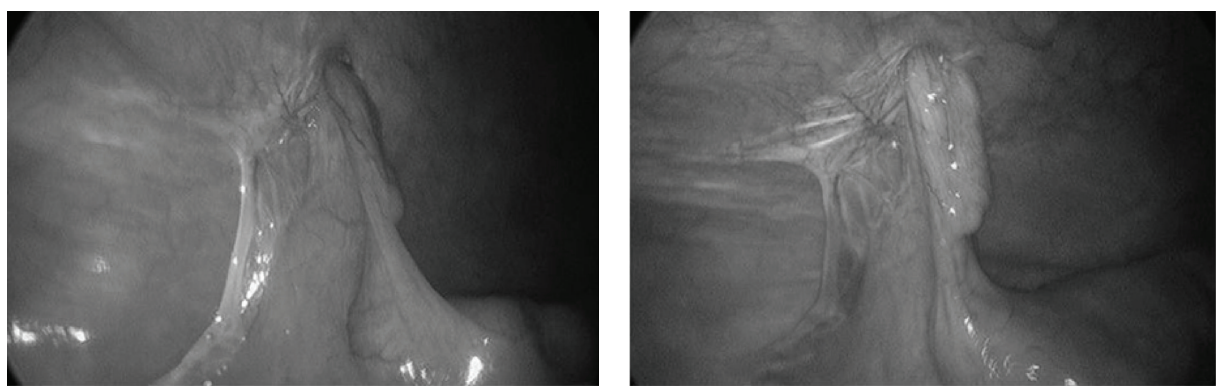

FIGURE 2: Intraoperative images demonstrating trocar site hernia containing the appendix.

using 0-Ethibond sutures passed transfascially using a suturepassing device. The patient was discharged home from the recovery room and had no postoperative complications at his 2-week follow-up visit. He has no evidence of hernia recurrence at 12 months.

\section{Discussion}

This case illustrates several salient points. While trocar site hernias are relatively rare following laparoscopic surgery, their morbidity can be significant. The relatively narrow aperture of these hernias can result in incarceration requiring an emergent operation and can lead to a bowel resection in rare circumstances. The incidence of overall trocar site hernia varies in the literature from 0 to $5.2 \%$ [1], with a recent systematic review showing a pooled incidence of $0.5 \%$ [2]. This review found that $82 \%$ of trocar site hernias occur at the umbilical port site and $96 \%$ of all port site hernias are associated with $10 / 12 \mathrm{~mm}$ trocar sites.
The data on trocar site hernia following robotic prostatectomy in the urology literature is even more limited with the two largest cohorts demonstrating incidences of $0.4 \%$ and $0.7 \%(2 / 498$ and $7 / 1055)$, respectively $[3,4]$. In these series, similar to the general trocar site literature, the majority of the hernias occurred at $12 \mathrm{~mm}$ sites. In the first series, both hernias occurred at the $12 \mathrm{~mm}$ umbilical trocar site [3], and in the second 6 of 7 hernias were at the $12 \mathrm{~mm}$ right lower quadrant port [4]. The findings in the second series likely reflect the increased use of larger right-sided trocar sites for the assistant's port so that sutures can be passed into the abdomen and handed to the robotic arms.

There have been rare reports of trocar site hernias containing the appendix (Table 1) [5-7]; however to our knowledge this is the first report of an appendix-containing trocar site hernia following robot-assisted laparoscopic prostatectomy. Helgstrand and colleagues reported a trend towards decreased incidence of hernia formation with fascial closure $(0.6 \%)$ versus no fascial closure (1.5\%). Additionally, they also found that increased trocar size was strongly associated with 
TABLE 1: Previous case reports describing trocar site hernias containing the appendix with subsequent intervention.

\begin{tabular}{lccccc}
\hline Author & Index operation & Trocar size & Onset of symptoms & Hernia contents & Treatment \\
\hline $\begin{array}{l}\text { Goodwin and } \\
\text { Ghilchik [5] }\end{array}$ & $\begin{array}{l}\text { Laparoscopic bilateral } \\
\text { inguinal hernia repair }\end{array}$ & Unknown & 36 months & Strangulated appendix & $\begin{array}{c}\text { Open appendectomy } \\
\text { and primary hernia } \\
\text { repair }\end{array}$ \\
$\begin{array}{l}\text { Menenakos } \\
\text { et al. [6] }\end{array}$ & $\begin{array}{l}\text { Laparoscopic low } \\
\text { anterior resection }\end{array}$ & $12 \mathrm{~mm}$ & 12 months & Incarcerated appendix & $\begin{array}{c}\text { Open appendectomy } \\
\text { and primary hernia } \\
\text { repair with mesh sublay }\end{array}$ \\
Latyf et al. [7] & $\begin{array}{c}\text { resection and partial } \\
\text { cystectomy for } \\
\text { colovesical fistula }\end{array}$ & $12 \mathrm{~mm}$ & 18 months & $\begin{array}{c}\text { Sliding hernia } \\
\text { containing the appendix }\end{array}$ & $\begin{array}{c}\text { Open appendectomy } \\
\text { and primary hernia } \\
\text { repair with mesh overlay }\end{array}$ \\
\hline
\end{tabular}

an increased rate of hernia formation [1]. Further, Azurin and colleagues performed a retrospective review of 1300 patients undergoing laparoscopic cholecystectomy and found a rate of trocar site hernia of $0.77 \%$, with all occurring at the $10 \mathrm{~mm}$ trocar site [8]. In addition, Erdas and colleagues found that $4.1 \%$ of 313 patients following laparoscopic cholecystectomy developed trocar site hernias over a mean follow-up period of 89.8 months [9]. $84.6 \%$ of these hernias occurred at the umbilicus while the remainder occurred at the $10 \mathrm{~mm}$ subxiphoid port. No trocar site hernias occurred at $5 \mathrm{~mm}$ ports or at $10 \mathrm{~mm}$ ports that were placed away from the midline.

In conclusion, with an increasing number of laparoscopic cases and therefore trocar site hernias, these hernias could continue to be a source of serious morbidity. Based on our review of the literature, we suggest that routine closure of $10-12 \mathrm{~mm}$ trocar sites should be the standard regardless of location, as this could decrease the risk of morbidity from trocar site hernias.

\section{Competing Interests}

The authors declare no conflict of interest whatsoever arising out of the publication of this manuscript.

\section{Acknowledgments}

This work received funding support from NIH, Grant no. T32-5T32CA090217-12.

\section{References}

[1] F. Helgstrand, J. Rosenberg, and T. Bisgaard, "Trocar site hernia after laparoscopic surgery: a qualitative systematic review," Hernia, vol. 15, no. 2, pp. 113-121, 2011.

[2] H. A. Swank, I. M. Mulder, C. F. La Chapelle, J. B. Reitsma, J. F. Lange, and W. A. Bemelman, "Systematic review of trocar-site hernia," British Journal of Surgery, vol. 99, no. 3, pp. 315-323, 2012.

[3] D. I. Kang, S. H. Woo, D. H. Lee, and I. Y. Kim, "Incidence of port-site hernias after robot-assisted radical prostatectomy with the fascial closure of only the midline 12 -mm port site," Journal of Endourology, vol. 26, no. 7, pp. 848-851, 2012.
[4] E. Chiong, P. K. Hegarty, J. W. Davis, A. M. Kamat, L. L. Pisters, and S. F. Matin, "Port-site hernias occurring after the use of bladeless radially expanding trocars," Urology, vol. 75, no. 3, pp. 574-580, 2010.

[5] A. T. Goodwin and M. Ghilchik, "Acute strangulation of the appendix within a laparoscopic port-site hernia," European Journal of Surgery, vol. 164, no. 2, pp. 151-152, 1998.

[6] C. Menenakos, N. Tsilimparis, N. Guenther, and C. Braumann, "Strangulated appendix within a trocar site incisional hernia following laparoscopic low anterior rectal resection. A case report," Acta Chirurgica Belgica, vol. 109, no. 3, pp. 411-413, 2009.

[7] R. Latyf, R. Slater, and J. Garner, "The vermiform appendix presenting in a laparoscopic port site hernia," Journal of Minimal Access Surgery, vol. 7, no. 3, pp. 181-183, 2011.

[8] D. J. Azurin, L. S. Go, L. R. Arroyo, and M. L. Kirkland, “Trocar site herniation following laparoscopic cholecystectomy and the significance of an incidental preexisting umbilical hernia," The American Surgeon, vol. 61, no. 8, pp. 718-720, 1995.

[9] E. Erdas, C. Dazzi, F. Secchi et al., "Incidence and risk factors for trocar site hernia following laparoscopic cholecystectomy: a long-term follow-up study," Hernia, vol. 16, no. 4, pp. 431-437, 2012. 


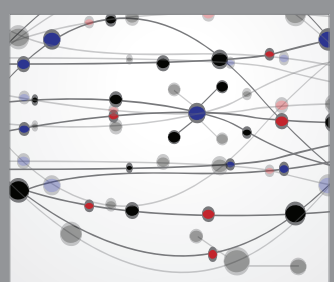

The Scientific World Journal
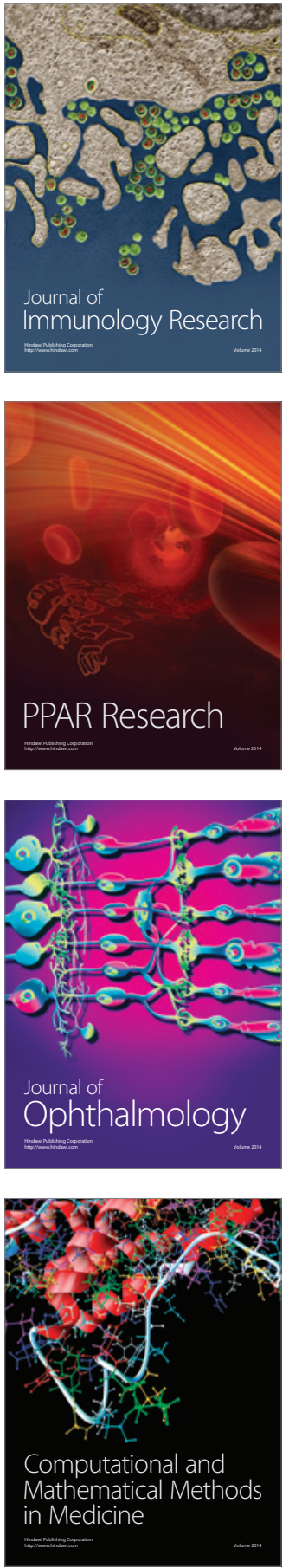

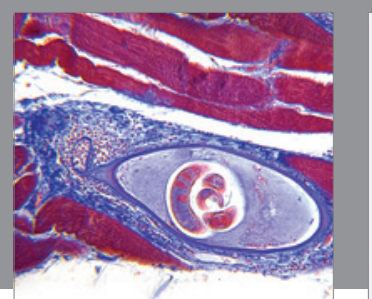

Gastroenterology Research and Practice

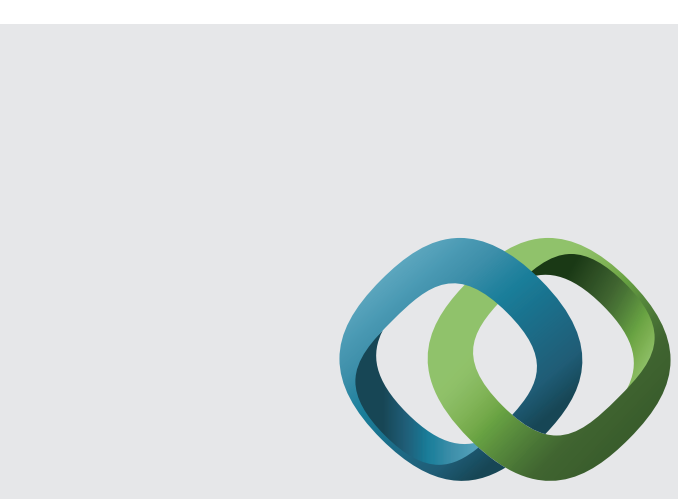

\section{Hindawi}

Submit your manuscripts at

http://www.hindawi.com
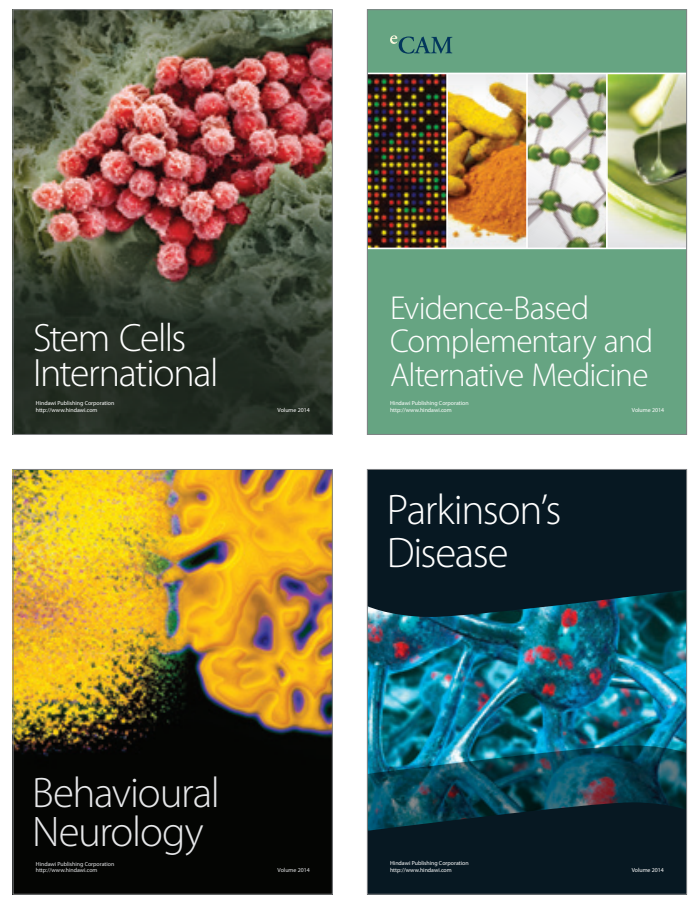
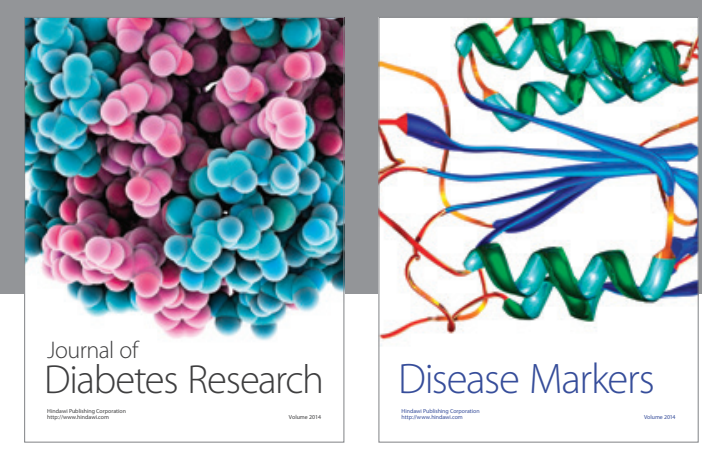

Disease Markers
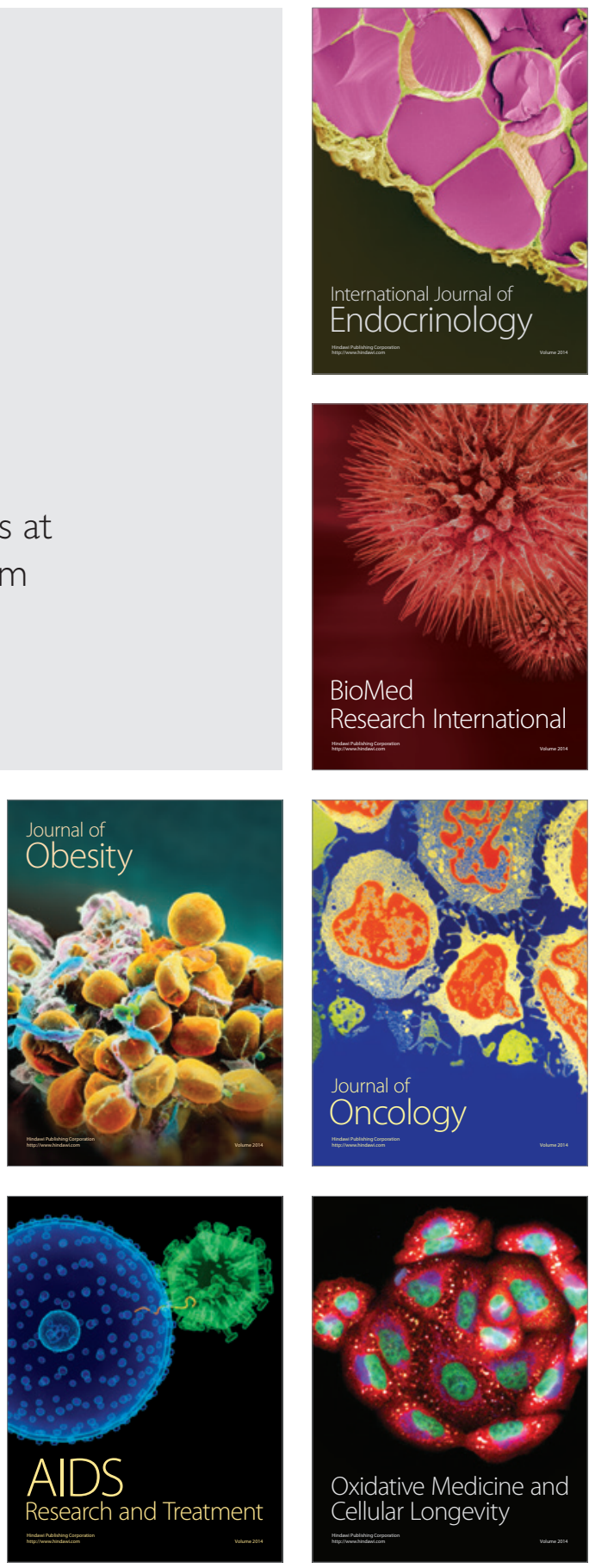